\title{
Dissolution and transformation of cerium oxide nanoparticles in plant growth media
}

\author{
Journal Article \\ Author(s): \\ Schwabe, Franziska; Schulin, Rainer; Rupper, Patrick; Rupper, Patrick; Stark, Wendelin; Nowack, Bernd \\ Publication date: \\ 2014-10 \\ Permanent link: \\ https://doi.org/10.3929/ethz-b-000092003 \\ Rights / license: \\ In Copyright - Non-Commercial Use Permitted \\ Originally published in: \\ Journal of Nanoparticle Research 16(10), https://doi.org/10.1007/s11051-014-2668-8
}




\title{
Dissolution and transformation of cerium oxide nanoparticles in plant growth media
}

\author{
Franziska Schwabe • Rainer Schulin • \\ Patrick Rupper • Aline Rotzetter • \\ Wendelin Stark $\cdot$ Bernd Nowack
}

Received: 8 August 2013/ Accepted: 20 September 2014/Published online: 8 October 2014

(C) Springer Science+Business Media Dordrecht 2014

\begin{abstract}
From environmental modeling of engineered nanomaterial (ENM) release, it is clear that ENMs will enter soils, where they interact with soil compounds as well as plant roots. We analyzed three different size groups of cerium dioxide nanoparticles $\left(\mathrm{CeO}_{2}\right.$-NPs) in respect to chemical changes in the most common plant growth medium, Hoagland solution. We created a simple environmental model using liquid dispersions of 9-, 23-, and 64-nm-uncoated $\mathrm{CeO}_{2}$-NPs. We found that $\mathrm{CeO}_{2}$-NPs release dissolved $\mathrm{Ce}$ when the $\mathrm{pH}$ of the medium is below 4.6 and in the presence of strong chelating agents even at $\mathrm{pH}$ of 8 . In addition, we found that in reaction with $\mathrm{Fe}^{2+}$-ions, equimolar amounts of $\mathrm{Ce}$ were released from NPs. We could
\end{abstract}

F. Schwabe $\cdot$ R. Schulin

Soil Protection, Institute of Terrestrial Ecosystems, ETH-

Zurich, Universitaetstrasse 16, 8092 Zurich, Switzerland

\section{P. Rupper}

Laboratory of Advanced Fibers, Empa-Swiss Federal Laboratories for Materials Science and Technology, Lerchenfeldstrasse 5, 9014 St. Gallen, Switzerland

A. Rotzetter - W. Stark

Department of Chemistry and Applied Biosciences, Institute for Chemical and Bioengineering, ETH Zurich, 8093 Zurich, Switzerland

B. Nowack $(\bowtie)$

Technology \& Society Laboratory, Empa-Swiss Federal Laboratories for Materials Science and Technology, Lerchenfeldstrasse 5, 9014 St. Gallen, Switzerland e-mail: nowack@empa.ch elucidate the involvement of the $\mathrm{CeO}_{2}$-NPs surface redox cycle between $\mathrm{Ce}^{3+}$ and $\mathrm{Ce}^{4+}$ to explain particle transformation. The chemical transformation of $\mathrm{CeO}_{2}$ NPs was summarized in four probable reactions: dissolution, surface reduction, complexation, and precipitation on the NP surface. The results show that $\mathrm{CeO}_{2}$-NPs are clearly not insoluble as often stated but can release significant amounts of $\mathrm{Ce}$ depending on the composition of the surrounding medium.

Keywords Nanoparticles $\cdot \mathrm{Ce}^{3+}$ and $\mathrm{Ce}^{4+}$. Dissolution · Hoagland medium $\cdot \mathrm{Fe}$ species . Environmental effects

\section{Introduction}

Engineered nanomaterials (ENMs) were intensely studied in the last 10 years. The broad variety of particle types, high production rates, and the use in costumer products have raised concerns about their release into the environment and their fate and effects after disposal (Gottschalk and Nowack 2011). The properties of ENMs are determined by their high surface-to-volume ratio, their crystal structure, and their reactive surface groups (Baalousha et al. 2010). The reactivity of ENMs is influenced by physicochemical features such as size, shape, surface coating, surface charge, bioavailability, specific surface area, and aggregation (Batley et al. 2013). Chemical and 
biochemical reactions like particle dissolution, adsorption of ions, interaction with cells, and uptake by organisms and combinations of these reactions are crucial to consider when studying the effects of ENMs on organisms in various environmental media (Handy et al. 2012; Baalousha et al. 2010; Scown et al. 2010).

In case of ENM emission (Gottschalk et al. 2009; Mueller and Nowack 2008; Nowack et al. 2012), plants are also of special interest since they are in direct contact with the important sinks: soil, air, and water (Miralles et al. 2012). As plants are the basis of the food chain, accumulation of ENMs in plants will allow them to pass through the food web (Ma et al. 2010). Zhu et al. (2008) were the first to observe ENM uptake by plants. Many studies on plant ENM uptake were carried out using aqueous suspensions or hydroponic media (Miralles et al. 2012). Cerium oxide nanoparticles $\left(\mathrm{CeO}_{2}-\mathrm{NPs}\right)$ were often used for these studies because they were considered to be stable and insoluble (Madler et al. 2002; Brunner et al. 2006) in dispersion and even after uptake (Zhang et al. 2011). $\mathrm{CeO}_{2}-\mathrm{NPs}$ are a good representative of ENMs because they are widely used, e.g., as catalyst, in fuel cells, for ceramic applications, and as diesel fuel additive (Baalousha et al. 2010). Recently, it was shown that $\mathrm{CeO}_{2}$-NPs can be incorporated into plant roots (Du et al. 2011) and even translocate into shoots (Zhang et al. 2011; Schwabe et al. 2013). Further Zhang et al. (2012) stated that $\mathrm{CeO}_{2}$-NPs do undergo biotransformation and are soluble to some extent in the presence of cucumber plants in hydroponic culture. Hence, the literature is contradictory about the potential solubility of $\mathrm{CeO}_{2}$-NPs. In mostly all available $\mathrm{CeO}_{2}$-NPs - plant studies, biotransformation and solubility of these NPs were not taken into account (Zhao et al. 2012; Wang et al. 2012).

Cerium naturally occurs in the Ce(III) and Ce(IV) oxidation states. $\mathrm{CeO}_{2}-\mathrm{NPs}$ are crystallized in a fluorite structure, where each $\mathrm{Ce}(\mathrm{IV})$ is surrounded by eight equivalent $\mathrm{O}^{2-}$-ions, which is a very stable conformation (Deshpande et al. 2005). In bulk $\mathrm{CeO}_{2}$, this atom conformation appears in $99.99 \%$ of the material and accounts for its insolubility (Baalousha et al. 2010). $\mathrm{CeO}_{2}$-NPs have the ability to absorb and release oxygen in a catalytic redox reaction on the surface. This feature plays a critical role in the overall performance of the catalytic activity of $\mathrm{CeO}_{2}-\mathrm{NPs}$ and makes it interesting for industrial use. The catalytic activity is due to the change in the oxidation state of $\mathrm{Ce}$ atoms on the NP surface between $\mathrm{Ce}^{3+}$ and $\mathrm{Ce}^{4+}$ depending on the oxygen partial pressure and the $\mathrm{pH}$ in the surrounding medium (Trovarelli et al. 2001; Ilan et al. 1976). Introduction of $\mathrm{Ce}^{3+}$ into the crystalline structure results in oxygen vacancies (Deshpande et al. 2005). Baalousha et al. (2010) found $60 \%$ of $\mathrm{Ce}^{3+}$ in $\mathrm{CeO}_{2}$-NPs of $25 \mathrm{~nm}$. The amount was significantly reduced when the NPs were dispersed in growth media. In a similar medium, van Hoecke et al. (2009) found only $0.3 \% \mathrm{Ce}^{3+}$ on the surface of $14-\mathrm{nm} \mathrm{CeO}_{2} \mathrm{NPs}$. Thill et al. (2006) found that the ratio between $\mathrm{Ce}^{3+}$ and $\mathrm{Ce}^{4+}$ was altered after adsorption on the outer membrane of E. coli in 7-nm $\mathrm{CeO}_{2}-\mathrm{NPs}$ from $4 \%$ of $\mathrm{Ce}^{3+}$ to $29 \%$ of $\mathrm{Ce}^{3+}$. Known as the cerium anomaly, oxides of $\mathrm{Ce}^{4+}$ are considered to be completely insoluble (Kakuwa and Matsumoto 2006), whereas $\mathrm{Ce}^{3+}$-oxide can be relatively soluble since it has a solubility product of $\log \mathrm{K}_{\mathrm{s}}=-21.5$ (Smith 2004).

Taking these studies together, the crystallite structure and lattice changes during redox reactions as well as the $\mathrm{Ce}^{3+}$ to $\mathrm{Ce}^{4+}$ ratios in $\mathrm{CeO}_{2}-\mathrm{NPs}_{\text {s he been well }}$ studied. But not a single report has combined the available information on structure and oxidation state and studied ion release from $\mathrm{CeO}_{2}-\mathrm{NPs}$ at the same time. Understanding the reactions of $\mathrm{CeO}_{2}-\mathrm{NPs}_{\text {disso- }}$ lution and transformation is essential for assessing toxicity and environmental fate. To evaluate realistic environmental scenarios, changes in chemical composition and physical features of particles need to be monitored already before they interact with organisms (Nowack et al. 2012). We studied $\mathrm{CeO}_{2}-\mathrm{NP}$ dissolution in the most common plant growth medium "Hoagland solution." Here, we evaluated the individual effects of the constituents of this medium on three different size groups of uncoated $\mathrm{CeO}_{2}$-NPs and monitored changes in the presence of gum arabic (GA) as representative of dissolved organic matter in such media.

\section{Materials and methods}

Nanoparticles

The cerium oxide nanoparticles used in this study were manufactured by flame-spray synthesis. By varying the manufacturing process, three different sizes were produced. They are referred to by their mean diameter size $(9,23$, and $64 \mathrm{~nm})$ obtained from TEM image evaluation of 100 single primary particles. Particles were noncoated $\mathrm{CeO}_{2}$-NPs. Flame-spray synthesis was 
performed using cerium 2-ethylhexanoic acid diluted in xylene ( $2 \mathrm{wt} \%$ for the $9-\mathrm{nm} \mathrm{CeO} \mathrm{Ce}_{2} \mathrm{NPs}$ and $8 \mathrm{wt} \%$ for the $23-\mathrm{nm} \mathrm{CeO}_{2}-\mathrm{NPs}$ ), which was introduced as a precursor into a methane/oxygen flame (Madler et al. 2002). For the 9-nm NPs, the flow rate of the precursor was $3 \mathrm{~mL} \mathrm{~min}^{-1}\left(5 \mathrm{~mL} \mathrm{~min}^{-1}\right.$ for the $23 \mathrm{~nm} \mathrm{CeO}_{2}$ -

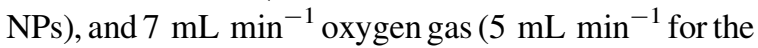
23-nm $\mathrm{CeO}_{2}$-NPs) was used to disperse the liquid leaving a capillary (Stark et al. 2003). The 64- $\mathrm{nm} \mathrm{CeO}_{2}$ NPs were made from $23-\mathrm{nm} \mathrm{CeO}_{2}$-NPs after sintering for $16 \mathrm{~h}$ at $700{ }^{\circ} \mathrm{C}$ (Limbach et al. 2005).

\section{BET, TEM, and XRD}

Particle size distributions and specific primary particle diameters were determined by Brunauer-EmmettTeller (BET) via $\mathrm{N}_{2}$ adsorption using a Micromeritics Tristar 3000 , by size surveying a 100 primary particles on images obtained by the means of transmission electron microscopy (TEM) (Tecnai F30 ST, FEI, operated at $300 \mathrm{kV}$ ), and by X-ray diffraction (XRD) (X'Pert PRO-MPD, $\mathrm{Cu} \mathrm{K \alpha}$ radiation, X'Celerator linear detector system, step size of $0.05^{\circ}, 45 \mathrm{kV}$, $40 \mathrm{~mA}$, and ambient conditions).

\section{X-ray photoelectron spectroscopy (XPS)}

Particle surface speciation and elemental content of surfaces were determined by means of XPS (PHI 5600 spectrometer, Physical Electronics, U.S.A) using nonmonochromatized $\mathrm{Mg}-K_{\alpha}$ radiation $(1253.6 \mathrm{eV})$. The spectra were collected at a photoemission angle of $45^{\circ}$ with respect to the surface normal. The operating pressure of the XPS analysis chamber was approximately $5 \times 10^{-9}$ Torr. We acquired survey scan spectra $(0-1,100 \mathrm{eV})$ and higher resolution narrow spectra for Ce. Curve fitting was carried out using CasaXPS software, Version 2.3.14. The potential charging of the sample surfaces was corrected by setting the graphitic and aliphatic $(\mathrm{C}-\mathrm{C}, \mathrm{C}-\mathrm{H})$ photoelectron signal contribution at $285.0 \mathrm{eV}$. Atomic ratios were calculated from XPS spectra after subtracting a Shirley-type background.

Particle composition

Total Ce was analyzed via X-ray fluorescence (XRF) (Spectro XEPOS Spectro Analytical Instruments, Germany). Samples were acquired by mixing $100 \mathrm{mg}$ of NPs with $3.9 \mathrm{~g}$ quartz purum (Fluka, 83340, Switzerland) in a laboratory shaker (MM200, Retsch, Switzerland). After homogeneous blending with $0.9 \mathrm{~g}$ wax (Cereox by Fluxana, BM-0002-1, Switzerland), a pellet was pressed at 15 bar.

To determine total carbon contents, $100 \mathrm{mg}$ samples of pure NP was analyzed in a TOC-L \& SSM 5000 A (Shimadzu, Japan).

Preparation of media and dispersions

All solutions were prepared with ultra-pure deionized water taken from a Millipore ${ }^{\circledR}$-unit (TKA GenPure, Germany), subsequently referred to as Millipore. For the preparation of Hoagland medium, different stock solutions were generated. These were 1:1000 diluted and mixed freshly for each experiment, resulting in $20 \%$ Hoagland medium, following Tandy et al. (2006). The final compositions of the medium were $800 \mu \mathrm{mol} / \mathrm{L}$ $\mathrm{Ca}\left(\mathrm{NO}_{3}\right)_{2}, 400 \mu \mathrm{mol} / \mathrm{L} \mathrm{MgSO}_{4}, 200 \mu \mathrm{mol} / \mathrm{L} \mathrm{KH}_{2} \mathrm{PO}_{4}$, $1,000 \mu \mathrm{mol} / \mathrm{L} \quad \mathrm{KNO}_{3}, \quad 10 \mu \mathrm{mol} / \mathrm{L} \quad \mathrm{Fe}(\mathrm{III})-\mathrm{ETDA}$, $20 \mu \mathrm{mol} / \mathrm{L} \quad \mathrm{H}_{3} \mathrm{BO}_{3}, \quad 4 \mu \mathrm{mol} / \mathrm{L} \quad \mathrm{MnSO}_{4}, \quad 0.4 \mu \mathrm{mol} / \mathrm{L}$ $\mathrm{ZnSO}_{4}, 0.4 \mu \mathrm{mol} / \mathrm{L} \mathrm{CuSO}_{4}, 0.4 \mu \mathrm{mol} / \mathrm{L} \mathrm{Na}_{2} \mathrm{MoO}_{4}$, and $10 \mu \mathrm{mol} / \mathrm{L} \mathrm{NaCl}$. Solutions were buffered using $5.1 \mathrm{mmol} / \mathrm{L}$ MES (2-N-morpholino-ethanesulfonic acid) and either $1 \mathrm{M} \mathrm{HCl}$ or $1 \mathrm{M} \mathrm{KOH}$ for $\mathrm{pH}$ adjustment.

Nanoparticles were dispersed using ultrasonication (Ultralab 4000, B. Braun, Germany) for $10 \mathrm{~min}$ at $160 \mathrm{~W}$ in Millipore. In all experiments which are marked "+ GA", gum arabic was added during this step. The concentration of GA was varied, proportional to the surface area of the NP group, for $9-\mathrm{nm} \mathrm{CeO}_{2} \rightarrow 90 \mathrm{mg} / \mathrm{L}$ $\mathrm{GA}, 23-\mathrm{nm} \mathrm{CeO} \mathrm{Ce}_{2} \rightarrow 15 \mathrm{mg} / \mathrm{L} \mathrm{GA}$, and for $64 \mathrm{~nm}-\mathrm{CeO}_{2}$ $\rightarrow 10 \mathrm{mg} / \mathrm{L} \mathrm{GA}$. The resulting suspension of $1 \mathrm{~g} / \mathrm{L} \mathrm{NPs}$, was diluted to a final concentration of $100 \mathrm{mg} / \mathrm{L} \mathrm{CeO}_{2^{-}}$ NPs in $20 \%$ Hoagland or solution of Hoagland component. All resulting dispersions were again adjusted to experimental requested $\mathrm{pH}$. Dispersions were incubated in 50-ml sample tubes at room temperature for 7 days on a shaded shaking device at $100 \mathrm{rpm}$ (Lab-shaker, Adolf Kühnert AG, Switzerland). The $\mathrm{pH}$ values stated in this study are the measured values of samples on $d 7$. All tested dispersions were generated in at least two individual replicates.

Characterization of $\mathrm{CeO}_{2}$-NPs in suspensions

Using a Zetasizer 3000 (Malvern, UK), the particle hydrodynamic diameters were determined in $\mathrm{nm}$ by 
dynamic light scattering (DLS) and the surface charges (zeta potentials in $\mathrm{mV}$ ) were determined by mobility measurements. For all suspensions 3 individual samples were analyzed, each in 5 technical replicates ( $4 \mathrm{~h}$ after NP ultrasonication).

\section{Analysis of Cerium}

Quantification of Ce content of NPs was carried out after a two-step acid digestion with conc. $\mathrm{HNO}_{3}$ for $60 \mathrm{~min}$ and in a 2nd step with $38 \% \mathrm{H}_{2} \mathrm{O}_{2}$ for another $90 \mathrm{~min}$. The microwave oven was set in both steps (lavis Ethos EM-2, MLS GmbH, Germany) at $165^{\circ} \mathrm{C}$ max. temperature. The solutions were analyzed for $\mathrm{Ce}$ using ICP-MS (ICP-MS-920, Varian, Switzerland).

For quantification of dissolved Ce (7 days of incubation), the NP dispersions were filtered through $10 \mathrm{kDa}$ Amicon ${ }^{\circledR}$ Ultra-4 Centrifugal Filter (Merck, Millipore, Switzerland) for $45 \mathrm{~min}$ at $4,000 \mathrm{rpm}$. The filtered solutions were measured via ICP-MS after addition of $1 \% \mathrm{HNO}_{3}$. The NP-free control media (without NPs) were analyzed in the same way as NP containing suspensions (the nutrient content of pure media was the same before and after filtration). The detection limit for Ce was $0.2 \mu \mathrm{g} / \mathrm{L}$, calculated from the count rate of 10 blank samples as mean + STDV, compared to the mean count rate + STDV of 10 measurements of the standard calibration solutions.

Speciation calculations

Speciation of $\mathrm{Ce}(\mathrm{III})$ in solution and precipitation of $\mathrm{Ce}(\mathrm{OH})_{3}$ and $\mathrm{Ce}(\mathrm{III}) \mathrm{PO}_{4}$ were calculated using VisualMinteQ with the stability constants given in the VisualMinteQ database (Gustafsson 2011). The total concentration of dissolvable Ce(III) was set at $23 \mu \mathrm{M}$, the values obtained by EDTA-extraction, accounting for $4.2 \%$ of the total $\mathrm{Ce}$ in the system.

\section{Results}

Particle characterization

TEM images of the three $\mathrm{CeO}_{2}$-particle groups used in this study are shown in Fig. 1. Particles were heterogeneous in size, but the size ranges of primary particles clearly separate all three groups. The groups were characterized using different techniques (Table 1). According to the TEM images of primary particles, the largest group (64 nm) was composed of $10 \%$ NPs larger than $100 \mathrm{~nm}$ and $2 \%$ under $30 \mathrm{~nm}$ but no NPs smaller than $25 \mathrm{~nm}$. In the $23 \mathrm{~nm}$ NP group, $50 \%$ of analyzed NPs were smaller than $20 \mathrm{~nm}$, the smallest NPs were $5 \mathrm{~nm}(1 \%)$ and the largest $80 \mathrm{~nm}(1 \%)$. The smallest NP group had a mean diameter of $9 \mathrm{~nm}$ and consisted of NPs with a minimal diameter of $4 \mathrm{~nm}$ to a maximum of $24 \mathrm{~nm}$ (Table 2).

The BET results showed that the mean surface area of the smallest group was 10 times higher than the 23-nm NPs and 47 times higher than the surface of 64-nm NPs.

The three particle groups were also characterized in suspension. After ultrasonication of the particles in Millipore water, the $\mathrm{pH}$ as well as the zeta potential differed strongly between the three particle groups. The smaller the particle diameter was, the higher was the zeta potential. In Hoagland solution or GA, the zeta potential changed to negative values, and the differences between the three particle groups were reduced.
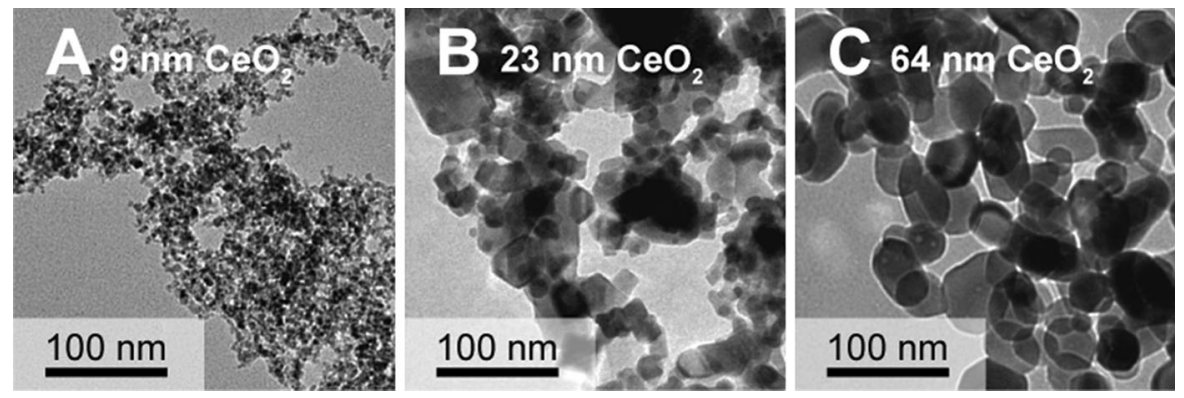

Fig. 1 TEM images of $\mathrm{CeO}_{2}$-NPs, after ultrasonic dispersion in Millipore with $100 \mu \mathrm{l} / \mathrm{L}$ polyacrylamide. a 9-nm particles, b 23-nm particles, and $\mathbf{c} 64-\mathrm{nm}$ particles 
Table 1 Characterization of $\mathrm{CeO}_{2}$-primary particles as obtained after flame-spray synthesis

\begin{tabular}{lllll}
\hline NP group & $\begin{array}{l}\text { TEM } \\
(\mathrm{nm})\end{array}$ & $\begin{array}{l}\text { XRD } \\
(\mathrm{nm})\end{array}$ & $\begin{array}{l}\text { BET } \\
\left(\mathrm{g} / \mathrm{m}^{2}\right)\end{array}$ & $\begin{array}{l}\text { XPS } \\
\left(\mathrm{Ce}^{3+}\right. \\
\text { in \% })\end{array}$ \\
\hline 9-nm CeO 2 & $8.9 \pm 4$ & $6.2 \pm 0.5$ & $233 \pm 0.4$ & 22.9 \\
23-nm CeO & $22.8 \pm 14$ & $27.7 \pm 1$ & $22.4 \pm 0.2$ & 11.1 \\
64-nm CeO & $63.9 \pm 28$ & $48.3 \pm 5$ & $4.9 \pm 0.1$ & 9.7 \\
\hline
\end{tabular}

Primary particle size measured: as diameter in $\mathrm{nm}$ by image recognition of TEM-pictures $(n=100)$; XRD-mean from 4 individual runs, given as calculated diameter in $\mathrm{nm}$; BET surface area, XPS for surface speciation of Ce given as $\% \mathrm{Ce}^{3+}$ on primary particle surface

The DLS size measurements given in Table 3 indicate that particles agglomerated fast and sizes exceeded $1,000 \mathrm{~nm}$ in $20 \%$ Hoagland medium when no stabilizing agent (gum arabic) was present.

\section{Surface speciation of Ce NPs}

In addition to the elements cerium, oxygen, carbon, and sulfur on the surface of the particles, the XPS survey scans showed significant amounts of sodium in the 23and 64-nm NP groups. No other elements were found.
Sulfur resulted from the sulfate groups present in the samples, whereas carbon came from the organic matrix. High-resolution spectra were measured for the element cerium. Caution must be taken when estimating the $\mathrm{Ce}(\mathrm{III})$ and $\mathrm{Ce}(\mathrm{IV})$ amounts from a sample using XPS. An overestimation of the $\mathrm{Ce}^{3+}$ concentration in ceria nanoparticles due to surface reduction of ceria in the XPS vacuum chamber enhanced by X-ray radiation has been reported (Zhang et al. 2004b). Therefore, to estimate the amounts of Ce(IV) and $\mathrm{Ce}(\mathrm{III})$, a reference sample of $\mathrm{Ce}(\mathrm{IV})$ was measured first. No significant amount of $\mathrm{Ce}$ (III) was found in the $\mathrm{Ce}$ (IV) reference sample. We therefore concluded that, under our experimental XPS conditions, a surface reduction of cerium in our XPS chamber is not a major issue. Based on these findings, spectra of the Ce(IV) speciation of the NP samples were measured. These spectra are given in Fig. 2 for the three NP groups: $9 \mathrm{~nm}$ (Fig. 2a), $23 \mathrm{~nm}$ (Fig. 2b), and $64 \mathrm{~nm}$ (Fig. 2c). The spectrum of cerium is rather complex, (spin-orbit splitting, hybridization with ligand orbitals and partial occupancy of the valence 4f orbital) but well known from the literature (Teterin et al. 1998; Zhang et al. 2004b). The experimental spectra (red lines) were

Table 2 Characterization of $\mathrm{CeO}_{2}$-NPs in suspensions

\begin{tabular}{|c|c|c|c|c|c|c|c|c|c|}
\hline \multirow[b]{2}{*}{ Medium } & \multicolumn{3}{|l|}{$\mathrm{pH}$} & \multicolumn{3}{|c|}{ DLS size $(\mathrm{nm})$} & \multicolumn{3}{|c|}{ Zeta potential $(\mathrm{mV})$} \\
\hline & 9 & 23 & 64 & 9 & 23 & 64 & 9 & 23 & 64 \\
\hline Millipore & 5.0 & 7.8 & 6.0 & $140 \pm 3$ & $129 \pm 1$ & $1,182 \pm 69$ & $44.9 \pm 6$ & $21.3 \pm 1$ & $7.4 \pm 0.3$ \\
\hline Millipore + GA & 5.2 & 7.4 & 6.3 & $244 \pm 9$ & $146 \pm 2$ & $260 \pm 10$ & $-24.7 \pm 6$ & $-26.2 \pm 1$ & $-18.1 \pm 0.2$ \\
\hline $\begin{array}{l}\text { Hoagland + GA } \\
\text { pH } 6\end{array}$ & 5.6 & 5.6 & 6.0 & $184 \pm 2$ & $166 \pm 3$ & $948 \pm 77$ & $-11.5 \pm 0.5$ & $-13.6 \pm 0.2$ & $-21.5 \pm 0.5$ \\
\hline $\begin{array}{l}\text { Hoagland without } \\
\text { GA pH } 6\end{array}$ & 5.6 & 5.6 & 6.0 & $3,023 \pm 263$ & $8,874 \pm 1,637$ & $29,410 \pm 4,086$ & $-9.2 \pm 4$ & $-16.4 \pm 0.3$ & $-26.5 \pm 0.8$ \\
\hline
\end{tabular}

Particle characteristics in different solutions $4 \mathrm{~h}$ after ultrasonication. $\mathrm{pH}$ of analyzed dispersion, DLS (dynamic light scattering) $n=3$, ZP (zeta potential) mean of 3 replicates, measured 5 times \pm STDV

Table 3 Characterization of $100 \mathrm{mg}$ primary $\mathrm{CeO}_{2}$ particles as obtained by flame-spray synthesis

\begin{tabular}{llllll}
\hline NP group & $\begin{array}{l}\text { Total } \\
\mathrm{Ce}(\%)\end{array}$ & $\begin{array}{l}\text { Total Ce } \\
(\mu \mathrm{mol} / 100 \mathrm{mg})\end{array}$ & $\begin{array}{l}\text { Total } \\
\text { Carbon }(\%)\end{array}$ & $\begin{array}{l}\text { Purity of } \\
\mathrm{CeO}_{2}(\%)\end{array}$ & $\begin{array}{l}\text { Total } \\
\mathrm{Ce}(\mu \mathrm{mol} / \mathrm{L})\end{array}$ \\
\hline $9-\mathrm{nm} \mathrm{CeO}_{2}$ & 77.2 & 551 & 1.2 & 96.3 & 488 \\
$23-\mathrm{nm} \mathrm{CeO}_{2}$ & 81.4 & 580 & 0.2 & 97.3 & 533 \\
$64-\mathrm{nm} \mathrm{CeO} \mathrm{C}_{2}$ & 85.2 & 607 & 0.05 & 97.8 & 545 \\
\hline
\end{tabular}

Particles were analyzed using XRF for total elements and TOC analyzer for total carbon content. The purity of the particles was calculated based on the stoichiometry of $\mathrm{CeO}_{2}$. For comparison, the Ce content measured by ICP-MS after acid digestion of $100 \mathrm{mg} / \mathrm{L}$ NPs is given in the last column as total $\mathrm{Ce}$ in $\mathrm{mg} / \mathrm{L}$ acid digest 


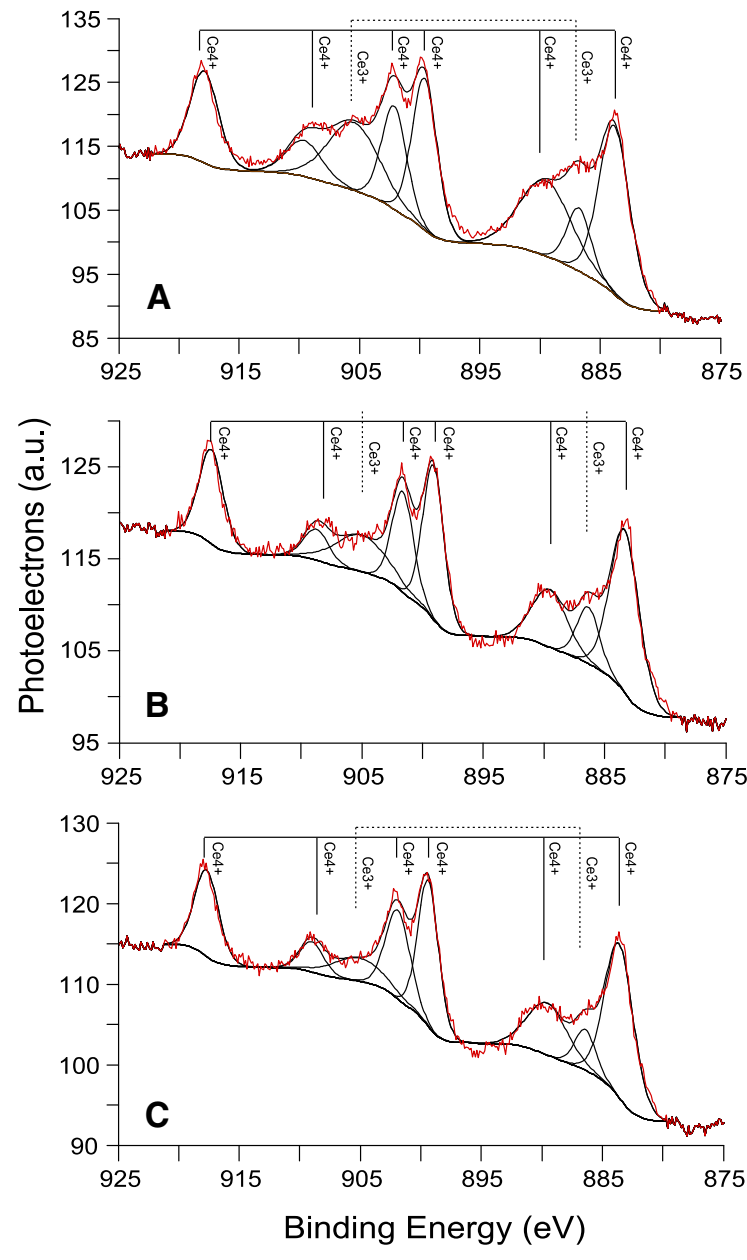

Fig. 2 XPS analysis of the Ce3d electrons in the three particle types. a Spectra of 9-nm $\mathrm{CeO}_{2}-\mathrm{NPs}$, b spectra of $23-\mathrm{nm} \mathrm{CeO}_{2}$ NPs, and c spectra of 64-nm $\mathrm{CeO}_{2}-\mathrm{NP}$

fitted after deconvolution into eight components (black lines) representing the various Ce peaks (six belonging to $\mathrm{Ce}^{4+}$ and two to $\mathrm{Ce}^{3+}$ ). The spin-orbit splitting was set to the values given by Teterin et al. (1998). All other energetic positions as well as all intensities and the full width at half maximum were determined by fitting. The single peak at $917.8 \mathrm{eV}$ was well separated from the other peaks and represented $\mathrm{Ce}^{4+}$ alone. It was used for a quantitative speciation of surface Ce(IV), as described by Li et al. (2004) and Pardo et al. (2007).

$\mathrm{Ce}^{4+\%}=\left(\right.$ Peak $\left._{917.8 \mathrm{ev}} \% / 14\right) \times 100$.

The corresponding amount of $\mathrm{Ce}^{3+} \%$ was calculated as $100 \%$ minus $\mathrm{Ce}^{4+} \%$ because only Ce(III) and $\mathrm{Ce}(\mathrm{IV})$ oxidation states of cerium were expected.
Based on literature, we assumed that the surface layer probed in these XPS measurements is $2 \mathrm{~nm}$ thick (Seah and Dench 1979). Since the XPS analyses could give the speciation of surface ion, the resulting percentage of $\mathrm{Ce}(\mathrm{III})$ in the surface layer is given in Table 1.

We used these amounts to calculate the $\mathrm{Ce}(\mathrm{III})$ content of the whole particle, assuming a spherical shape. Since redox-reactions between $\mathrm{Ce}^{3+} / \mathrm{Ce}^{4+}$ are known to occur only on the NP surface, we expected that the NP core consists of $100 \% \mathrm{Ce}^{4+}$ (Baalousha et al. 2010). The particle core was defined as NP diameter-2-nm surface layer (Wu et al. 2004). Based on these assumptions we calculated the overall $\mathrm{Ce}$ (III) fraction for each NP group: $19 \%$ in the $9 \mathrm{~nm}-\mathrm{NPs}$, $4.8 \%$ in the $23 \mathrm{~nm}$, and $1.7 \%$ in the $64-\mathrm{nm}$ particles.

Dissolution of particles in Hoagland medium

In all tested suspensions, the initial concentration of $\mathrm{CeO}_{2}$-NPs was $100 \mathrm{mg} / \mathrm{L}$ (equal to $0.58 \mathrm{mmol} / \mathrm{L}$ ). Using the XRF measurements given in Table 3, we calculated the total amount of $\mathrm{Ce}$ in solution, which would occur in the case of complete NP dissolution as $551 \mu \mathrm{mol} / \mathrm{L}$ for $9-\mathrm{nm}$ NPs, $580 \mu \mathrm{mol} / \mathrm{L}$ for $23 \mathrm{~nm}$ NPs, and $607 \mu \mathrm{mol} / \mathrm{L}$ for $64-\mathrm{nm}$ NPs. Table 3 also gives the amounts of total Ce content of a $100 \mathrm{mg} / \mathrm{L}$ NPs after acid digestion. These values were lower than XRF-values probably due to losses during the digestion or dilution. However, both methods indicated that the biggest NP group has the highest purity, which is likely due to the sintering process during production.

Figure 3a shows the dissolved Ce concentration for the three size groups after 7 days of incubation in $20 \%$ Hoagland solution, in Hoagland with additional $\mathrm{GA}$, and in phosphate-free Hoagland solution. At $\mathrm{pH} 6$ without GA, only the 9-nm NPs released a detectable amount of $\mathrm{Ce}(0.04 \mu \mathrm{mol} / \mathrm{L})$ into solution, but when GA was present, it released $0.06 \mu \mathrm{mol} / \mathrm{L}$ of $\mathrm{Ce}$. The presence of GA resulted in a significant increase in $\mathrm{Ce}$ release from the 9-nm particles at $\mathrm{pH} 4$. When the $\mathrm{pH}$ of the suspension was below 4.5, all three $\mathrm{CeO}_{2}-\mathrm{NPs}$ released much higher amounts of $\mathrm{Ce}$. The order of $\mathrm{Ce}$ release was $9>23>64 \mathrm{~nm}$. The release of Ce was far higher from 9- to 23-nm NPs, when no phosphate was present in the medium. At $\mathrm{pH} 4$ without phosphate, 38 times more $\mathrm{Ce}$ were released from 9-nm NPs $(9.96 \mu \mathrm{mol} / \mathrm{L})$ than in the presence of phosphate. This amount is $1.8 \%$ of the total amount of 

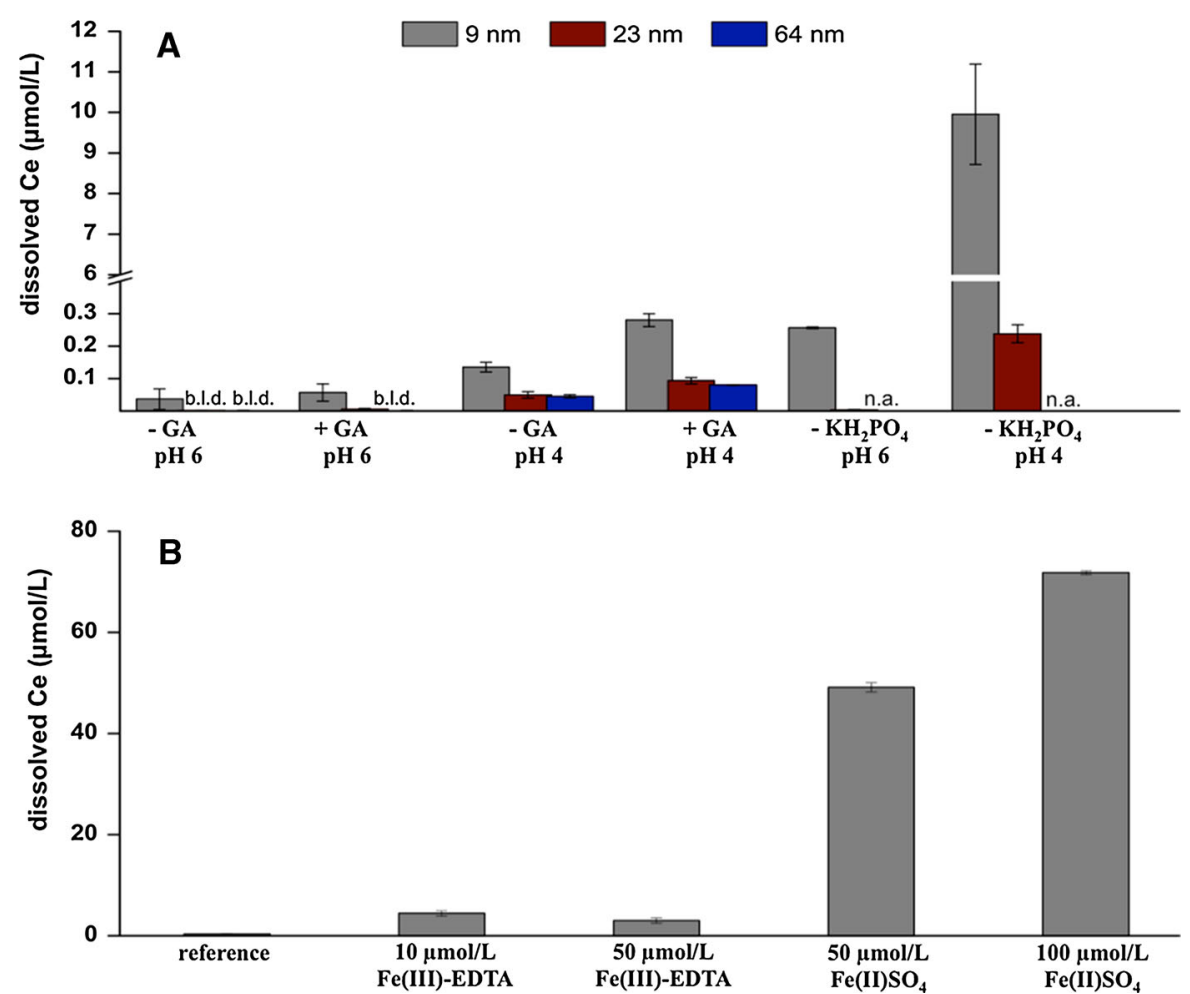

Fig. 3 Amount of dissolved Ce from $100 \mathrm{mg} / \mathrm{L} \mathrm{CeO}_{2}$-NPs. a in $20 \%$ Hoagland solution after 7 days of incubation. $-\mathrm{GA}=$ no gum arabic was added, $+\mathrm{GA}=$ gum arabic was added; $-\mathrm{KH}_{2} \mathrm{PO}_{4}=$ no phosphate and no gum arabic was added. All dispersions were prepared at least in duplicate; error bars indicate standard error over all replicates per dispersion. b.l.d = below limits of detection, n.a. = not annotated (64-nm NPs were not measured in $20 \%$ Hoagland without $\mathrm{KH}_{2} \mathrm{PO}_{4}$ because no detectable amount of $\mathrm{Ce}$ was expected). Break in $y$-axis:

Ce in suspension. The bigger 23-nm particles released less ions, but in the absence of phosphate, these NPs released 2.5 times more Ce compared to the same dispersion with phosphate.

Dissolution of $\mathrm{CeO}_{2}$-NPs in presence of single Hoagland components

Since the smallest particles released the highest amounts of $\mathrm{Ce}$, they were further used to analyze the influence of single Hoagland components on $\mathrm{Ce}$ on solubility. To get a clear picture of the chemistry behind NPs dissolution, 9-nm NPs were tested at $\mathrm{pH}$ 4.5 with the single components present in $20 \%$ Hoagland. In Fig. 3b, the average amount of released $\mathrm{Ce}$ in $800 \mu \mathrm{mol} / \mathrm{L} \mathrm{CaNO}_{3}, 800 \mu \mathrm{mol} / \mathrm{L} \quad \mathrm{MgSO}_{4}$,
0.4-6 $\mu \mathrm{mol} / \mathrm{L}$ b Amount of dissolved Ce from 9-nm $\mathrm{CeO}_{2}$ group $(100 \mathrm{mg} / \mathrm{L})$ after 7 days of incubation, in the presence of different Fe species. The "reference" sample shows the mean value of dissolved $\mathrm{Ce}$ in different Hoagland components. $\mathrm{pH}$ values of dispersions: reference, $\mathrm{pH} 4.3 ; 10 \mu \mathrm{mol} / \mathrm{L} \mathrm{Fe}$ (III)EDTA, $\mathrm{pH} 4.5 ; 50 \mu \mathrm{mol} / \mathrm{L}$ Fe(III)EDTA, $\mathrm{pH} 4.5 ; 50 \mu \mathrm{mol} / \mathrm{L}$ $\mathrm{Fe}(\mathrm{II}) \mathrm{SO}_{4}, \mathrm{pH} 4.8$; and $100 \mu \mathrm{mol} / \mathrm{L} \mathrm{Fe}(\mathrm{II}) \mathrm{SO}_{4}, \mathrm{pH} 4.5 ; n=3$, error bars indicate standard error of replicates

$1,000 \mu \mathrm{mol} / \mathrm{L} \mathrm{KNO}_{3}$, and $1 \mathrm{~g} / \mathrm{L}$ MES hydrate is used as the reference value, because there were no significant differences between $\mathrm{Ce}$ dissolution in the presence of all these compounds. Besides phosphate, we found that $\mathrm{Fe}$ species strongly influenced NPs dissolution. 10 or $50 \mu \mathrm{mol} / \mathrm{L} \mathrm{Fe}$ (III)EDTA resulted in 4.4 and $3.0 \mu \mathrm{mol} / \mathrm{L}$ detectable $\mathrm{Ce}$ ions, respectively. Very high amounts of Ce were released when $\mathrm{Fe}$ was supplied as Fe(II). In dispersion of NPs with $50 \mu \mathrm{mol} / \mathrm{L}$ $\mathrm{Fe}^{2+}$, we detected $49.1 \mu \mathrm{mol} / \mathrm{L} \mathrm{Ce}$ ions and in $100 \mu \mathrm{mol} / \mathrm{L} \mathrm{Fe} \mathrm{Fe}^{2+} 71.8 \mu \mathrm{mol} / \mathrm{L}$. This means that almost equimolar amounts of $\mathrm{Ce}$ were released when $\mathrm{Fe}^{2+}$ was present. These results were obtained in dispersions under standard atmosphere. When $\mathrm{O}_{2}$ was displaced by $\mathrm{N}_{2}$, the amounts of released Ce did not change (data not shown). 
Estimating dissolvable Ce content of NPs by EDTA-complexation

EDTA is a very strong chelating agent that forms strong complexes with trivalent ions and thus enhances the dissolution of oxides (Stumm 1992). For an estimation of the dissolvable $\mathrm{Ce}$, particles were incubated with $50 \mu \mathrm{mol} / \mathrm{L}$ EDTA-acid (Fig. 4). We detected $23 \mu \mathrm{mol} / \mathrm{L}$ Ce with $9-\mathrm{nm}$ NPs, $0.33 \mu \mathrm{mol} / \mathrm{L}$ Ce with $23-\mathrm{nm} \mathrm{NPs}$, and $0.12 \mu \mathrm{mol} / \mathrm{L}$ with the $64-\mathrm{nm}$ NP group, after 7 days of incubation. The results were the same at $\mathrm{pH}$ values below 4.6 or above 6 . From these results, the percentage of maximum dissolvable Ce was calculated as $4.2 \%$ for $9-n m$ NPs, $0.06 \%$ for 23-nm NPs, and $0.02 \%$ for 64-nm NPs. The concentration of dissolved Ce after incubation with EDTAacid is higher compared to incubation with Fe-EDTA, because $\mathrm{Fe}^{3+}$ is a competing ion for complexation (Fig 5).

\section{Discussion}

Our results show that $\mathrm{CeO}_{2}-\mathrm{NPs}$ are not stable in Hoagland medium but do readily dissolve. We centralize four main factors that influenced the dissolution of $\mathrm{CeO}_{2}$-NPs: (i) size of primary particle; (ii) $\mathrm{pH}$ of suspension; (iii) extent of agglomeration/ aggregation in suspension; and (iv) the presence of chemical binding or reaction partners like phosphate or reducing agents like $\mathrm{Fe}(\mathrm{II}) \mathrm{SO}_{4}$.

Fig. 4 Amount of dissolved Ce from $100 \mathrm{mg} / \mathrm{L}$ $\mathrm{CeO}_{2}$-NPs in $50 \mu \mathrm{mol} / \mathrm{L}$ EDTA after 7 days of incubation. Break in $y$-axis: $1-17 \mu \mathrm{mol} / \mathrm{L} ; n=3$, error bars indicate standard error over all replicates per dispersion
Concerning factor 1: we found that the smaller the primary particle size was, the more dissolved Ce was released. In our study, the largest NP group (64 nm) was almost insoluble. The smaller particles contained far more Ce(III). Deshpande et al. (2005) demonstrated that small $\mathrm{CeO}_{2}$-NPs face a high lattice strain when $\mathrm{Ce}^{3+}$ is introduced because of a larger ionic radius compared to $\mathrm{Ce}^{4+}$. This lattice strain increases exponentially when particle size is below $25 \mathrm{~nm}$ (Zhang et al. 2004a). Particles below $20 \mathrm{~nm}$, like in our case, have a strong need for lattice relaxation, which is acquired by insertion of oxygen vacancies into the crystal lattice. As a result, even more Ce(III)

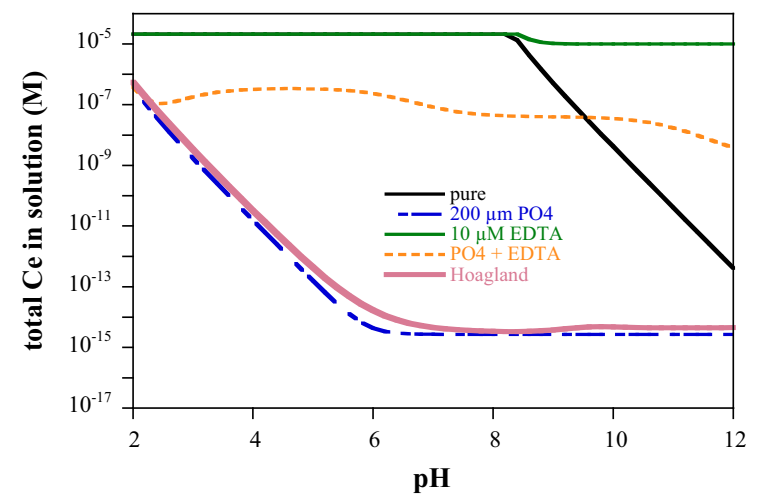

Fig. 5 Solubility of $\mathrm{CeOH}_{3}$ (total $\mathrm{Ce} 23 \mu \mathrm{M}$ ) in the presence of different media at the point of thermodynamic equilibrium in pure water, $200 \mu \mathrm{mol} / \mathrm{L} \mathrm{PO}_{4}, 10 \mu \mathrm{mol} / \mathrm{L}$ EDTA, $200 \mu \mathrm{mol} / \mathrm{L}$ $\mathrm{PO}_{4}+10 \mu \mathrm{mol} / \mathrm{L}$ EDTA, and complete $20 \%$ Hoagland solution

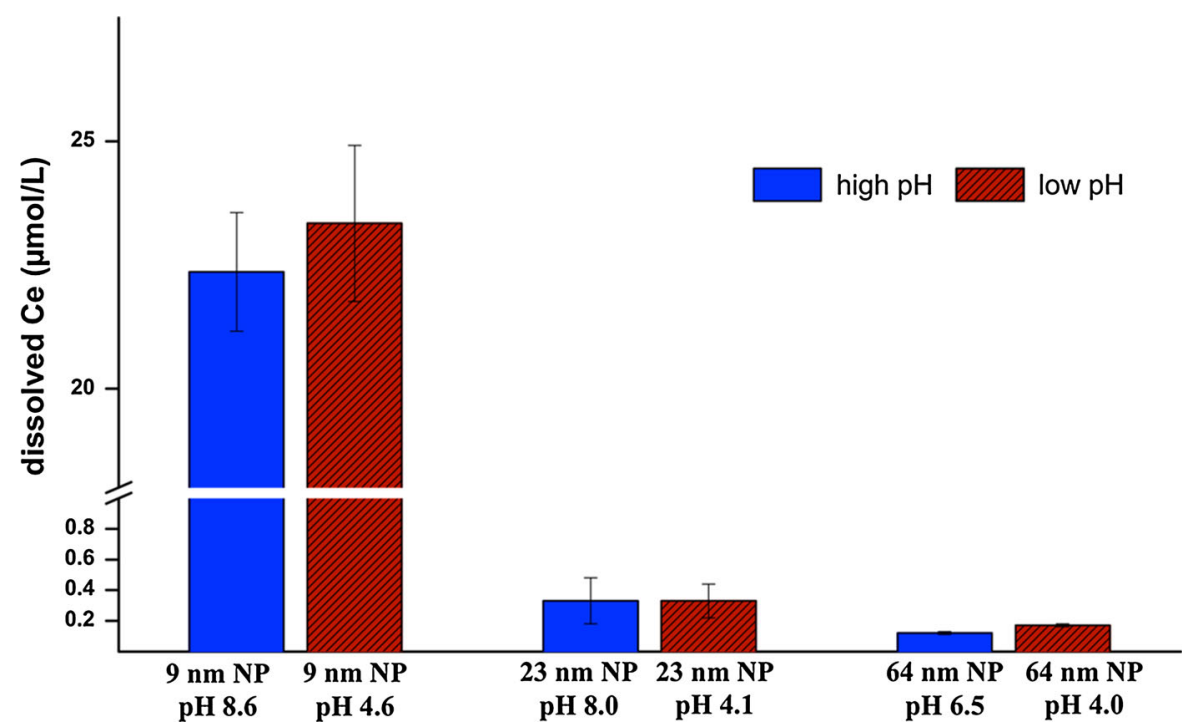


can be introduced into the crystal lattice (Tsunekawa et al. 1999).

In alkaline conditions, the oxidation of $\mathrm{Ce}^{3+}$ to $\mathrm{Ce}^{4+}$ is preferred, whereas in acidic media, the reduction of $\mathrm{Ce}$ is higher (Trinidad et al. 2008). Since $\mathrm{Ce}^{3+}$ is the more soluble ion, a decrease in the $\mathrm{pH}$ of the dispersion leads to higher Ce release from NPs. Our data confirmed this for all three NP groups in Hoagland medium. Only when the $\mathrm{pH}$ was below 5, all three size groups released detectable amounts of $\mathrm{Ce}$.

The modeling of $\mathrm{Ce}(\mathrm{OH})_{3}$ solubility indicated that it is completely soluble up to $\mathrm{pH} 8$ in pure water. Consequently, any $\mathrm{Ce}^{3+}$ present on the surface of $\mathrm{CeO}_{2}$ could be completely dissolved from the NPs up to this $\mathrm{pH}$. The speciation calculation showed the maximum possible dissolved concentration at the point of thermodynamic equilibrium. But dissolution reactions of metal oxides are known to be kinetically slow, especially at higher $\mathrm{pH}$ (Stumm 1992) and the thermodynamic equilibrium had presumably not been reached in our samples after 7 days, which may explain the lower dissolved Ce concentrations compared to the modeled values.

The influence of GA as an organic matter representative was well pronounced in Hoagland medium by increasing Ce solubility. There are two possible explanations for these results. Firstly, GA prevents agglomeration and aggregation (Schwabe et al. 2013), thus NP sedimentation is slowed and a large reaction surface is maintained for a longer period, as indicated in this study by the smaller hydrodynamic diameter of all NPs when GA was present. Or secondly, the reactive groups of GA form a complex with $\mathrm{Ce}$ in the (III+) oxidation state and keep it stable in solution, similar to EDTA-complexation. Besides natural organic matter, small organic ligands might dissolve ions from $\mathrm{CeO}_{2}$-NPs, like oxalate, citrate, and ascorbate (Cervini-Silva et al. 2005).

In the presence of EDTA, equimolar Ce amounts can be solubilized (up to $\mathrm{pH}$ 12). This high solubility of $\mathrm{Ce}^{3+}$ in the presence of EDTA (log K Ce(III)EDTA of 15.93) (Smith 2004) forms the basis for assessing the possible amount of $\mathrm{Ce}$ that can be solubilized from $\mathrm{CeO}_{2}$-NPs. For 9-nm particles, this fraction was $4.2 \%$; the fraction of $\mathrm{Ce}^{3+}$ calculated from the XPS data was $19 \%$, thus approximately one fourth of the $\mathrm{Ce}^{3+}$ of NPs is close enough to the surface to be solubilized under optimal conditions in the presence of a strong chelating agent. The calculations also suggest that $200 \mu \mathrm{mol} / \mathrm{L}$ phosphate (the concentration in $20 \%$ Hoagland solution) would result in very low dissolved Ce concentrations above $\mathrm{pH} 4$, caused by the very low solubility of $\mathrm{Ce}(\mathrm{III}) \mathrm{PO}_{4}$. Singh et al. 2011 stated that the redox cycle between $\mathrm{Ce}^{3+}$ and $\mathrm{Ce}^{4+}$ can be blocked by phosphate since it can trap Ce in the Ce(III) oxidation state (Singh et al. 2011). Zhang et al. 2012 found $\mathrm{Ce}(\mathrm{III}) \mathrm{PO}_{4}$ formation in hydroponic medium around the roots of cucumber. $\mathrm{Ce}(\mathrm{III}) \mathrm{PO}_{4}$ immobilizes free Ce by precipitation on the particle surface (Zhang et al. 2012). In Hoagland solution, the phosphate content determined the solubility of $\mathrm{Ce}$; the presence of EDTA had only a small influence because it was added as $\mathrm{Fe}$ (III)EDTA $(\log \mathrm{K} 27.2)$, which is a more stable complex than Ce(III)EDTA (log K 15.9) (Smith 2004). Summarizing our recent findings and the existing literature, $\mathrm{Ce}(\mathrm{III}) \mathrm{PO}_{4}$ is the most likely form into which $\mathrm{CeO}_{2}$ is transformed.

When $\mathrm{Fe}(\mathrm{II})$ was present as a reducing agent in acidic conditions, the dissolved concentrations of $\mathrm{Ce}$ were almost equimolar to the initial $\mathrm{Fe}(\mathrm{II})$, even in the presence of oxygen, which could have driven the oxidation of $\mathrm{Ce}^{3+}$ back into $\mathrm{Ce}^{4+}$. These results indicate that once $\mathrm{Ce}^{3+}$ is formed on the particle surface, it is released from the particle and subjacent Ce can be reduced, as illustrated in the following chemical equation:

$$
\begin{aligned}
\mathrm{Ce}^{4+}+\mathrm{Fe}^{2+} \rightarrow & \mathrm{Ce}^{3+}+\mathrm{Fe}^{3+} \\
& \left(\mathrm{Ce}^{4+}+\mathrm{e}^{-} \rightarrow \mathrm{Ce}^{3+} / \mathrm{Fe}^{2+} \rightarrow \mathrm{e}^{-}+\mathrm{Fe}^{3+}\right) .
\end{aligned}
$$

The high solubility of $\mathrm{CeO}_{2}$ in the presence of $\mathrm{Fe}^{2+}$ may have profound implications for the stability of $\mathrm{CeO}_{2}$-NPs in natural systems. Free $\mathrm{Fe}^{2+}$ can be present in wastewater and occur in sediments under anoxic conditions. $\mathrm{CeO}_{2}$-NPs may therefore not be stable in two of the most relevant systems for ENM as determined from modeling studies (Gottschalk et al. 2009), wastewater treatment plants and sediments (Phillips and Lovley 1987).

In summary, our results indicate that the following four reactions are involved in the transformation of $\mathrm{CeO}_{2}$-NPs in the environment (Fig. 6). Firstly, the dissolution of $\mathrm{Ce}$ in the (III+) oxidation state occurs due to its relatively high solubility (Kakuwa and Matsumoto 2006). Further $\mathrm{Ce}^{4+}$ can be reduced to $\mathrm{Ce}^{3+}$ and then be released. Reduction occurs predominantly in acidic media and may need an electron donor-like $\mathrm{Fe}^{2+}$. Complexation is another, but very 


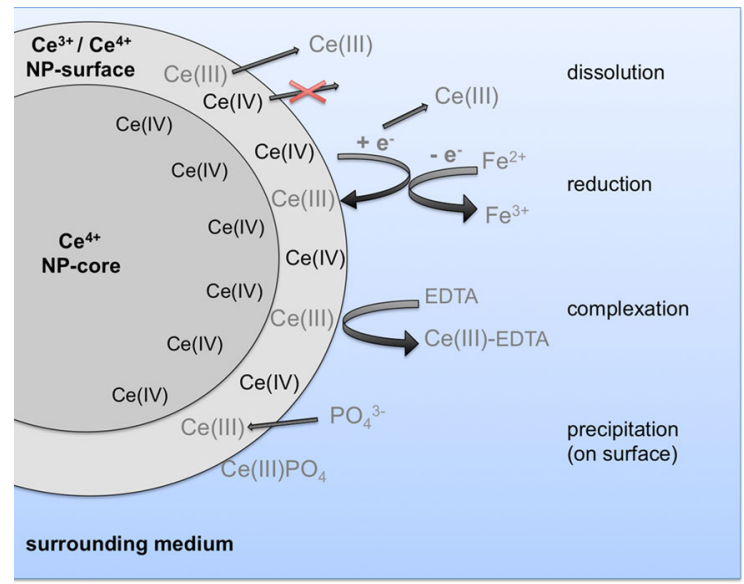

Fig. 6 Scheme of possible chemical reactions taking place on the surface and in the surrounding medium of $\mathrm{CeO}_{2}-\mathrm{NPs}$ when free ions/chelating agents are present

effective, way of transforming $\mathrm{CeO}_{2}$-NPs. As we demonstrated in the presence of EDTA, very high amounts of dissolved Ce can be detected. Different anthropogenic chelating agents are found in natural water. In the effluents of wastewater treatment plants, high amounts of EDTA of up to $17 \mu \mathrm{M}$ have been measured (Nowack and VanBriesen 2005). We assume that GA might function in a similar way as EDTA in increasing the soluble Ce fraction.

The fourth important reaction was precipitation. Similar to Baalousha et al. (2010), we found less released $\mathrm{Ce}$ when phosphate was present in the media. This indicates that $\mathrm{Ce}^{3+}$ is not dissolved from the surface but trapped most likely by $\mathrm{CePO}_{4}$ formation on the NP surface.

\section{Conclusions}

For estimating the fate and effect of nanoparticles in ecosystems, chemical transformation especially dissolution needs to be considered. We emphasize that $\mathrm{CeO}_{2}-\mathrm{NPs}$, which are often described to be very stable, like in waste incineration plants (Walser et al. 2012), can undergo dissolution or other chemical transformations. To estimate the dissolvable amount of NPs, we suggest the easy method of extracting surface ions via a strong chelating agent (e.g. EDTA).

Acknowledgments We kindly acknowledge Dr. Thomas Bucheli and Alexander Gogos from Agroscope Reckenholz-
Tänikon (ART) for their support in DLS and zeta potential measurements. We thank Dr. Susan Tandy for language corrections. Financial support by the ETH-Zurich (ETHIIRA Project, ETH- 21 08-3) was kindly acknowledged.

\section{References}

Baalousha M, Le Coustumer P, Jones I, Lead JR (2010) Characterisation of structural and surface speciation of representative commercially available cerium oxide nanoparticles. Environ Chem 7(4):377-385

Batley GE, Kirby JK, McLaughlin MJ (2013) Fate and risks of nanomaterials in aquatic and terrestrial environments. Acc Chem Res 46(3):854-862

Brunner TJ, Wick P, Manser P, Spohn P, Grass RN, Limbach LK, Bruinink A, Stark WJ (2006) In vitro cytotoxicity of oxide nanoparticles: comparison to asbestos, silica, and the effect of particle solubility. Environ Sci Technol 40:4374-4381

Cervini-Silva J, Fowle DA, Banfield J (2005) Biogenic dissolution of a soil cerium-phosphate mineral. Am J Sci 305(6-8):711-726

Deshpande S, Patil S, Kuchibhatla SVNT, Seal S (2005) Size dependency variation in lattice parameter and valency states in nanocrystalline cerium oxide. Appl Phys Lett 87(13): 133113

Du WC, Sun YY, Ji R, Zhu JG, Wu JC, Guo HY (2011) TiO2 and $\mathrm{ZnO}$ nanoparticles negatively affect wheat growth and soil enzyme activities in agricultural soil. J Environ Monit 13(4):822-828

Gottschalk F, Nowack B (2011) The release of engineered nanomaterials to the environment. $\mathrm{J}$ Environ Monit 13(5):1145-1155

Gottschalk F, Sonderer T, Scholz RW, Nowack B (2009) Modeled environmental concentrations of engineered nanomaterials ( $\mathrm{TiO} 2, \mathrm{ZnO}, \mathrm{Ag}, \mathrm{CNT}$, fullerenes) for different regions. Environ Sci Technol 43:9216-9222

Gustafsson JP (2011) Visual MINTEQ version 3.0. http:// www2.lwr.kth.se/English/Oursoftware/vminteq/index.html. Accessed 1 Oct 2014

Handy RD, Cornelis G, Fernandes T, Tsyusko O, Decho A, Sabo-Attwood T, Metcalfe C, Steevens JA, Klaine SJ, Koelmans AA, Horne N (2012) Ecotoxicity test methods for engineered nanomaterials: practical experiences and recommendations from the bench. Environ Toxicol Chem 31(1):15-31

Hoecke KV, Quik JTK, Mankiewicz-Boczek J, Schamphelaere KACD, Elsaesser A, Meeren PVd, Barnes C, McKerr G, Howard CV, Meent DVD, Rydzyński K, Dawson KA, Salvati A, Lesniak A, Lynch I, Silversmit G, Samber BrD, Vincze L, Janssen CR (2009) Fate and effects of CeO2 nanoparticles in aquatic ecotoxicity tests. Environ Sci Technol 43(12):4537-4546. doi:10.1021/es9002444

Ilan YA, Czapski G, Meisel D (1976) The one-electron transfer redox potentials of free radicals. I. The oxygen/superoxide system. Biochim Biophys Acta 430(2):209-224

Kakuwa Y, Matsumoto R (2006) Cerium negative anomaly just before the Permian and Triassic boundary event-the upward expansion of anoxia in the water column. Palaeogeogr Palaeoclimatol Palaeoecol 229(4):335-344 
Li ZM, Zhu FR, Zhang ZB, Ren XJ, Deng H, Zhai LH, Zhang LX (2004) Laser resonance ionization spectroscopy of even-parity autoionization states of cerium atom. Guang pu xue yu guang pu fen $x i=$ Guang pu 24(12):1494-1498

Limbach LK, Li YC, Grass RN, Brunner TJ, Hintermann MA, Muller M, Gunther D, Stark WJ (2005) Oxide nanoparticle uptake in human lung fibroblasts: effects of particle size, agglomeration, and diffusion at low concentrations. Environ Sci Technol 39(23):9370-9376. doi:10.1021/es051043o

Ma XM, Geiser-Lee J, Deng Y, Kolmakov A (2010) Interactions between engineered nanoparticles (ENPs) and plants: phytotoxicity, uptake and accumulation. Sci Total Environ 408(16):3053-3061

Madler L, Stark WJ, Pratsinis SE (2002) Flame-made ceria nanoparticles. J Mater Res 17(6):1356-1362

Miralles P, Church TL, Harris AT (2012) Toxicity, uptake, and translocation of engineered nanomaterials in vascular plants. Environ Sci Technol 46(17):9224-9239

Mueller NC, Nowack B (2008) Exposure modeling of engineered nanoparticles in the environment. Environ Sci Technol 42(12):4447-4453

Nowack B, VanBriesen J (eds) (2005) Chelating agents in the environment. In: Biogeochemistry of chelating agents, vol 910. ACS Symposium Series, pp 1-18

Nowack B, Ranville JF, Diamond S, Gallego-Urrea JA, Metcalfe C, Rose J, Horne N, Koelmans AA, Klaine SJ (2012) Potential scenarios for nanomaterial release and subsequent alteration in the environment. Environ Toxicol Chem 31(1):50-59

Pardo A, Merino MC, Arrabal R, Viejo F, Munoz JA (2007) Ce conversion and electrolysis surface treatments applied to A3xx.x alloys and A3xx.x/SiCp composites. Appl Surf Sci 253(6):3334-3344

Phillips EJP, Lovley DR (1987) Determination of Fe(Iii) and $\mathrm{Fe}(\mathrm{Ii})$ in Oxalate Extracts of Sediment. Soil Sci Soc Am J 51(4):938-941

Schwabe F, Schulin R, Limbach LK, Stark W, Burge D, Nowack B (2013) Influence of two types of organic matter on interaction of $\mathrm{CeO} 2$ nanoparticles with plants in hydroponic culture. Chemosphere 91(4):512-520. doi:10.1016/j. chemosphere.2012.12.025

Scown TM, Santos EM, Johnston BD, Gaiser B, Baalousha M, Mitov S, Lead JR, Stone V, Fernandes TF, Jepson M, van Aerle R, Tyler CR (2010) Effects of aqueous exposure to silver nanoparticles of different sizes in rainbow trout. Toxicol Sci 115(2):521-534. doi:10.1093/Toxsci/Kfq076

Seah MP, Dench WA (1979) Quantitative electron spectroscopy of surfaces: a standard data base for electron inelastic mean free paths in solids. Surf Interface Anal 1(1):2-11

Singh S, Dosani T, Karakoti AS, Kumar A, Seal S, Self WT (2011) A phosphate-dependent shift in redox state of cerium oxide nanoparticles and its effects on catalytic properties. Biomaterials 32(28):6745-6753. doi:10.1016/j. biomaterials.2011.05.073

Smith RM, Martell AE (2004) NIST critically selected stability constants of metal complexes, version 2.0. U.S. Department of Commerce, Gaithersburg

Stark WJ, Madler L, Maciejewski M, Pratsinis SE, Baiker A (2003) Flame synthesis of nanocrystalline ceria-zirconia: effect of carrier liquid. Chem Commun 5:588-589. doi:10. 1039/b211831a

Stumm W (1992) Chemistry of the solid-water interface: processes at the mineral-water and particle-water interface in natural systems. Wiley, New York

Tandy S, Schulin R, Nowack B (2006) The influence of EDDS on the uptake of heavy metals in hydroponically grown sunflowers. Chemosphere 62(9):1454-1463

Teterin YA, Teterin AY, Lebedev AM, Utkin IO (1998) The XPS spectra of cerium compounds containing oxygen. J Electron Spectrosc 88:275-279

Thill A, Zeyons O, Spalla O, Chauvat F, Rose J, Auffan M, Flank AM (2006) Cytotoxicity of $\mathrm{CeO}_{2}$ nanoparticles for Escherichia coli. Physico-chemical insight of the cytotoxicity mechanism. Environ Sci Technol 40:6151-6156

Trinidad P, de Leon CP, Walsh FC (2008) The use of electrolyte redox potential to monitor the $\mathrm{Ce}(\mathrm{IV}) / \mathrm{Ce}(\mathrm{III})$ couple. J Environ Manage 88(4):1417-1425

Trovarelli A, Boaro M, Rocchini E, de Leitenburg C, Dolcetti G (2001) Some recent developments in the characterization of ceria-based catalysts. J Alloy Compd 323:584-591

Tsunekawa S, Sahara R, Kawazoe Y, Ishikawa K (1999) Lattice relaxation of monosize $\mathrm{CeO} 2-\mathrm{x}$ nanocrystalline particles. Appl Surf Sci 152(1-2):53-56

Walser T, Limbach LK, Brogioli R, Erismann E, Flamigni L, Hattendorf B, Juchli M, Krumeich F, Ludwig C, Prikopsky K, Rossier M, Saner D, Sigg A, Hellweg S, Gunther D, Stark WJ (2012) Persistence of engineered nanoparticles in a municipal solid-waste incineration plant. Nat Nanotechnol 7(8):520-524

Wang Z, Xie X, Zhao J, Liu X, Feng W, White JC, Xing B (2012) Xylem- and phloem-based transport of $\mathrm{CuO}$ nanoparticles in maize (Zea mays L.). Environ Sci Technol 46(8):4434-4441. doi:10.1021/es204212z

Wu LJ, Wiesmann HJ, Moodenbaugh AR, Klie RF, Zhu YM, Welch DO, Suenaga M (2004) Oxidation state and lattice expansion of $\mathrm{CeO} 2$-x nanoparticles as a function of particle size. Phys Rev B 69(12):125415

Zhang F, Jin Q, Chan SW (2004a) Ceria nanoparticles: size, size distribution, and shape. J Appl Phys 95(8):4319-4326

Zhang F, Wang P, Koberstein J, Khalid S, Chan SW (2004b) Cerium oxidation state in ceria nanoparticles studied with X-ray photoelectron spectroscopy and absorption near edge spectroscopy. Surf Sci 563(1-3):74-82

Zhang ZY, He X, Zhang HF, Ma YH, Zhang P, Ding YY, Zhao YL (2011) Uptake and distribution of ceria nanoparticles in cucumber plants. Metallomics 3(8):816-822

Zhang P, Ma YH, Zhang ZY, He X, Zhang J, Guo Z, Tai RZ, Zhao YL, Chai ZF (2012) Biotransformation of ceria nanoparticles in cucumber plants. ACS Nano 6(11):9943-9950

Zhao LJ, Peralta-Videa JR, Varela-Ramirez A, Castillo-Michel H, Li CQ, Zhang JY, Aguilera RJ, Keller AA, GardeaTorresdey JL (2012) Effect of surface coating and organic matter on the uptake of $\mathrm{CeO} 2 \mathrm{NPs}$ by corn plants grown in soil: insight into the uptake mechanism. J Hazard Mater 225:131-138

Zhu H, Han J, Xiao JQ, Jin Y (2008) Uptake, translocation, and accumulation of manufactured iron oxide nanoparticles by pumpkin plants. J Environ Monit 10:713-717 